\title{
Initial stages of growth and the influence of temperature during chemical vapor deposition of $\mathbf{s p}^{2}$-BN films
}

\author{
Mikhail Chubarov, Henrik Pedersen, Hans Högberg, and Anne Henrya) \\ Department of Physics, Chemistry and Biology, Linköping University, SE-581 83 Linköping, Sweden \\ Zsolt Czigány \\ Institute of Technical Physics and Materials Science, Centre for Energy Research of Hungarian Academy \\ of Sciences, Konkoly-Thege Miklós út 29-33, H-1121 Budapest, Hungary
}

(Received 6 August 2015; accepted 23 October 2015; published 11 November 2015)

\begin{abstract}
Knowledge of the structural evolution of thin films, starting by the initial stages of growth, is important to control the quality and properties of the film. The authors present a study on the initial stages of growth and the temperature influence on the structural evolution of $\mathrm{sp}^{2}$ hybridized boron nitride (BN) thin films during chemical vapor deposition (CVD) with triethyl boron and ammonia as precursors. Nucleation of hexagonal $\mathrm{BN}$ (h-BN) occurs at $1200{ }^{\circ} \mathrm{C}$ on $\alpha-\mathrm{Al}_{2} \mathrm{O}_{3}$ with an AlN buffer layer $\left(\mathrm{AlN} / \alpha-\mathrm{Al}_{2} \mathrm{O}_{3}\right)$. At $1500^{\circ} \mathrm{C}, \mathrm{h}-\mathrm{BN}$ grows with a layer-by-layer growth mode on $\mathrm{AlN} / \alpha-\mathrm{Al}_{2} \mathrm{O}_{3}$ up to $\sim 4 \mathrm{~nm}$ after which the film structure changes to rhombohedral $\mathrm{BN}(\mathrm{r}-\mathrm{BN})$. Then, r-BN growth proceeds with a mixed layer-by-layer and island growth mode. h-BN does not grow on $6 \mathrm{H}-\mathrm{SiC}$ substrates; instead, r-BN nucleates and grows directly with a mixed layer-by-layer and island growth mode. These differences may be caused by differences in substrate surface temperature due to different thermal conductivities of the substrate materials. These results add to the understanding of the growth process of $\mathrm{sp}^{2}$-BN employing CVD. ( 2015 American Vacuum Society. [http://dx.doi.org/10.1116/1.4935155]
\end{abstract}

\section{INTRODUCTION}

Growth of thin film materials with well-defined mechanical, optical, and electrical properties is vital for many application areas in today's society. However, the aforementioned properties are highly dependent on, for instance: the composition, the microstructure, including the surface structure, the level of stress, and grain size. For many applications, there is a need to control all aspects of the thin film growth process, i.e., the initial formation of the nuclei on the substrate, their coalescence to form a continuous layer, and finally, the continued growth on this first layer to form a film of desired thickness. For the semiconductor materials AlN and $\mathrm{GaN}$, the growth mechanisms on both $\alpha-\mathrm{Al}_{2} \mathrm{O}_{3}$ and $\mathrm{SiC}$ substrates are well investigated, allowing for high quality films to be deposited reproducibly. On $\alpha-\mathrm{Al}_{2} \mathrm{O}_{3}$, a buffer layer is needed for deposition of high quality material. Usually, this layer is a GaN or an AlN layer grown at a low temperature $^{1}$ and where layer-by-layer growth mode is observed after coalescence of the nucleation islands. ${ }^{2,3}$ The critical thickness for GaN growth on $\alpha-\mathrm{Al}_{2} \mathrm{O}_{3}$ with an $\mathrm{AlN}$ buffer layer before the onset for dislocations due to lattice mismatch has been experimentally determined to be $2.9 \mathrm{~nm}$. This is in good agreement with the calculated value of $3.15 \mathrm{~nm}$, using the equation derived by Fischer et al. ${ }^{4,5}$ On $\mathrm{SiC}$ substrates, a similar behavior to that of $\mathrm{GaN}$ on $\alpha-\mathrm{Al}_{2} \mathrm{O}_{3}$ is observed for growth of GaN, while AlN solely proceeds in a layer-by-layer growth mode. ${ }^{6}$

The literature on nucleation and growth of boron nitride (BN) is sparse-especially for the $\mathrm{sp}^{2}$-hybridized phases like hexagonal BN (h-BN) and rhombohedral BN (r-BN). Studies

${ }^{\text {a)} E l e c t r o n i c ~ m a i l: ~ a n n e . h e n r y @ l i u . s e ~}$ on the growth of $\mathrm{sp}^{2}$-BN by chemical vapor deposition (CVD) on different substrates $\left(\mathrm{Si}, \mathrm{SiO}_{2} / \mathrm{Si}\right.$, quartz, $\alpha-\mathrm{Al}_{2} \mathrm{O}_{3}$, $\mathrm{SiC}, \mathrm{Ni}, \mathrm{Ru}$, and $\mathrm{Cu}$ ) and employing different boron $\left[\mathrm{B}\left(\mathrm{C}_{2} \mathrm{H}_{5}\right)_{3}, \mathrm{~B}_{2} \mathrm{H}_{6}, \mathrm{BCl}_{3}, \mathrm{BH}_{3}-\mathrm{NH}_{3}\right.$, and $\left.\mathrm{B}_{3} \mathrm{~N}_{3} \mathrm{H}_{6}\right]$ and nitrogen $\left(\mathrm{NH}_{3}, \mathrm{~N}\right.$-plasma) precursors can be found in the literature. ${ }^{7-15}$ The growth of $\mathrm{sp}^{2}-\mathrm{BN}$ on metallic substrates is stimulated by the catalytic activity of the substrates usually employed $(\mathrm{Ni}, \mathrm{Ru}, \mathrm{Cu}$, and $\mathrm{Pt})$ and is conducted at a low growth temperature (ca. $1000^{\circ} \mathrm{C}$ ) but is limited to the growth of only a few basal planes of $\mathrm{sp}^{2}$-BN before the catalytic metal surface is covered by BN. ${ }^{16-19}$ The surface morphology of such films provides insights into the initial stages of thin film growth. In most cases, formation of triangularshaped islands on the substrate occurs leading to the conclusion that island growth mode is obtained. ${ }^{20-22}$ Sutter et al..$^{23}$ reported uniform coverage of the substrate with a few layers of $\mathrm{sp}^{2}$-BN basal planes (up to five) that suggests layerby-layer growth mode, using growth by reactive magnetron sputtering. Most studies reporting on the growth of $\mathrm{sp}^{2}-\mathrm{BN}$ on $\mathrm{Si}, \alpha-\mathrm{Al}_{2} \mathrm{O}_{3}$, and $\mathrm{SiC}$ substrates focus on the determination of the properties and quality of the deposited films while information on the initial stages of the growth is still lacking. ${ }^{8,9,14}$

For CVD of $\mathrm{sp}^{2}-\mathrm{BN}$, an AlN buffer layer supports the growth of $\mathrm{r}-\mathrm{BN}$ on $\alpha-\mathrm{Al}_{2} \mathrm{O}_{3}$ substrates while no buffer layer was necessary to deposit $\mathrm{r}$-BN on c-axis oriented $\mathrm{SiC}^{24,25}$ Recently, we observed growth of h-BN on AlN buffer layer to a thickness of $\sim 4 \mathrm{~nm}$ with a following transition to $\mathrm{r}-\mathrm{BN}$ growth while polytype pure r-BN was observed on $\mathrm{SiC}$ substrates. ${ }^{26}$ In the present study, we report on the nucleation and early stages of $\mathrm{sp}^{2}-\mathrm{BN}$ growth on $\alpha-\mathrm{Al}_{2} \mathrm{O}_{3}$ and $\mathrm{SiC}$ substrates for polytype and morphology control of $\mathrm{sp}^{2}-\mathrm{BN}$ films deposited by CVD. The formation of crystalline forms of 
$\mathrm{sp}^{2}$-BN was investigated in the temperature range between 1200 and $1700^{\circ} \mathrm{C}$, to determine the growth conditions that favor the formation of $\mathrm{r}-$ or $\mathrm{h}-\mathrm{BN}$.

\section{EXPERIMENTAL PROCEDURES}

To investigate the initial stages of growth for $\mathrm{sp}^{2}-\mathrm{BN}$ thin films on $\alpha-\mathrm{Al}_{2} \mathrm{O}_{3}$ with an AlN buffer layer $\left(\mathrm{AlN} / \alpha-\mathrm{Al}_{2} \mathrm{O}_{3}\right)$ and on-axis (0001) $6 \mathrm{H}-\mathrm{SiC}$ substrates, we employed hot wall CVD at a temperature of $1500^{\circ} \mathrm{C}$ for $1,5,10$, and $20 \mathrm{~min}$ of growth. A number of deposition experiments were carried out on both substrates at $120{ }^{\circ} \mathrm{C}$ and on $(0001) 6 \mathrm{H}-\mathrm{SiC}$ at 1600 and $1700^{\circ} \mathrm{C}$. Triethylboron $\left[\mathrm{B}\left(\mathrm{C}_{2} \mathrm{H}_{5}\right)_{3}, \mathrm{TEB}\right]$ and ammonia $\left(\mathrm{NH}_{3}\right)$ diluted in hydrogen $\left(\mathrm{H}_{2}\right)$ gas were the boron and nitrogen precursors, respectively. The TEB vapor was delivered into the reaction cell as carried by hydrogen gas that was bubbled through a stainless steel bubbler with the TEB liquid held at a constant pressure of $600 \mathrm{mbar}$ and a constant temperature of $0{ }^{\circ} \mathrm{C}$. This resulted in a TEB vapor pressure in the bubbler of $\sim 20$ mbar and with a TEB concentration in the total gas mixture of $135 \mathrm{ppm}$. The gaseous ammonia was fed to the reaction cell from a gas bottle. The flow was adjusted to obtain a nitrogen to boron ratio (N/B) of 643 at a growth temperature of $1500{ }^{\circ} \mathrm{C}$ and a ratio of 750 at a growth temperature of $1200^{\circ} \mathrm{C}$. In addition, silane $\left(\mathrm{SiH}_{4}\right)$ diluted in hydrogen to a concentration of $2000 \mathrm{ppm}$ was added to the gas mixture to a total $\mathrm{SiH}_{4}$ concentration of $5 \mathrm{ppm}$ at $1500^{\circ} \mathrm{C}$ and $1.2 \mathrm{ppm}$ at $1200^{\circ} \mathrm{C}$ following our previous results on the effect of silicon during growth of $\mathrm{sp}^{2}$-BN thin films. ${ }^{27}$ All depositions were conducted at a constant pressure of 70 mbar as controlled by a throttle valve installed before the process pump. The substrates were cleaned following the Radio Corporation of America procedure that includes removal of organic contaminants by water solution of ammonia and hydrogen peroxide followed by the removal of inorganic contaminants by water solution of hydrochloric acid and hydrogen peroxide. ${ }^{28}$ Prior to the thin film deposition, both types of substrates were in situ pretreated, where an AlN buffer layer was formed on $\alpha-\mathrm{Al}_{2} \mathrm{O}_{3}$ by nitridation at the applied growth temperature using ammonia at a total concentration of $10 \%$ in hydrogen for 10 min (Ref. 24) or by the introduction of silane into the reactor at the temperature of $950{ }^{\circ} \mathrm{C}$ in order to improve the $6 \mathrm{H}-\mathrm{SiC}$ substrate surface morphology. ${ }^{29}$

The characterization of the h-BN and r-BN structures is complicated as they show the same in-plane lattice constants $(2.504 \AA$ ) and the same spacing between the basal planes (ca. $3.333 \AA$ ). When the film is grown epitaxially along the c-axis, h-BN and r-BN are difficult to distinguish by $\mathrm{x}$-ray diffraction (XRD) in the Bragg-Brentano geometry $(\theta-2 \theta$ scan) or by transmission electron microscopy (TEM). However, it is possible to distinguish between them by observing the stacking sequence of the basal planes in atomic resolution TEM or by performing XRD measurements of diffraction peaks characteristic of the h-BN and r-BN phases. As a consequence, there are reports showing the formation of $\mathrm{h}-\mathrm{BN}$ and $\mathrm{r}-\mathrm{BN}$ when different growth conditions are employed. ${ }^{23,30}$ In addition to these two crystalline forms of
$\mathrm{sp}^{2}$-BN, two less ordered forms exist: turbostratic (t-) and amorphous (a-) BN. The lack of ordering between basal planes is characteristic for t-BN, which means that the basal planes are randomly rotated with respect to each other and do not have strictly defined spacing between them. This results in a slightly larger spacing between the basal planes compared to $\mathrm{r}-$ and $\mathrm{h}-\mathrm{BN}$, and where t-BN exhibits low intensity broad peaks in $\mathrm{x}$-ray diffraction that is shifted to lower $2 \theta$ angles. In our previous work, we showed that the theoretically possible stackings of $\mathrm{sp}^{2}$-BN layers predicted by Ooi et $a .^{31}$ are similar in $\mathrm{x}$-ray diffraction to $\mathrm{h}-\mathrm{BN}$ and should not be confused with $\mathrm{r}-\mathrm{BN}$. $^{26}$

XRD was used to determinate the structural properties of the deposited films. XRD measurements were performed by employing PANalytical EMPYREAN MRD X-Ray diffractometer equipped with a $\mathrm{Cu}$-anode $\mathrm{x}$-ray tube and 5-axis $(x-y-z-\chi-\varphi)$ sample stage. For the determination of the crystalline structure of the thin films, glancing incidence XRD (GI-XRD) and investigation of asymmetric planes were conducted. GI-XRD allows for extracting information from the in-plane ordering of the film since the $\mathrm{x}$-ray scattering vector is close to the sample surface plane (angles slightly higher than the critical angle for the material). Such geometry increases the sampling volume of the material. For these measurements, capillary optics on the incident beam side and parallel plate collimator on the detector side were used. The $\mathrm{Cu} \mathrm{K}_{\beta}$ line was removed by a Ni filter.

The stacking sequence and microstructure was assessed by electron microscopy from a JEOL 3010 instrument operated at an acceleration voltage of $300 \mathrm{kV}$ and with $1.7 \AA$ point resolution. The sample was prepared in the way that it was cut along the [1100] direction perpendicular to the (0001) plane of the h-BN as discussed in our previous work. ${ }^{26}$ Such preparation allows the stacking sequence of the basal planes to be determined, and the atomic resolution in TEM makes it possible to distinguish between $\mathrm{r}-\mathrm{BN}$ and h-BN. Further, the TEM sample was prepared to a typical dimension of $1.8 \times 0.5 \times 0.5 \mathrm{~mm}^{3}$ and were mounted and glued on a Ti grid ${ }^{32}$ followed by mechanical thinning, polishing, and dimpling to a thickness of $\sim 20 \mu \mathrm{m}$ in the middle. Thinning to electron transparency was achieved by ion beam milling with $10 \mathrm{keV} \mathrm{Ar}^{+}$ions at an incidence angle of $4^{\circ}$ with respect to the surface. To minimize surface amorphization in the final period of the milling process, the ion energy was decreased gradually to $250 \mathrm{eV}$.

To study the formation of $\mathrm{B}-\mathrm{N}$ bonds at the initial stages of growth, we applied x-ray photoelectron spectroscopy (XPS) in a MICROLAB 310-F equipped with twin anode $\mathrm{x}$-ray tube and using only the $\mathrm{Al} \mathrm{K}_{\alpha}$ line at generator settings of $15 \mathrm{kV}$ and $20 \mathrm{~mA}$ and $5 \times 2 \mathrm{~mm}^{2}$ area of the sample being analyzed. A spherical sector analyzer and five channels detector were used to determine the energy of the photoelectrons emitted from the sample. The energy scale was calibrated from electrons emitted from the Fermi level that should have $0 \mathrm{eV}$ binding energy in XPS.

Scanning electron microscopy (SEM) with a Leo 1550 instrument equipped with a field-emission gun was used to study the surface morphology of the deposited films. For the 

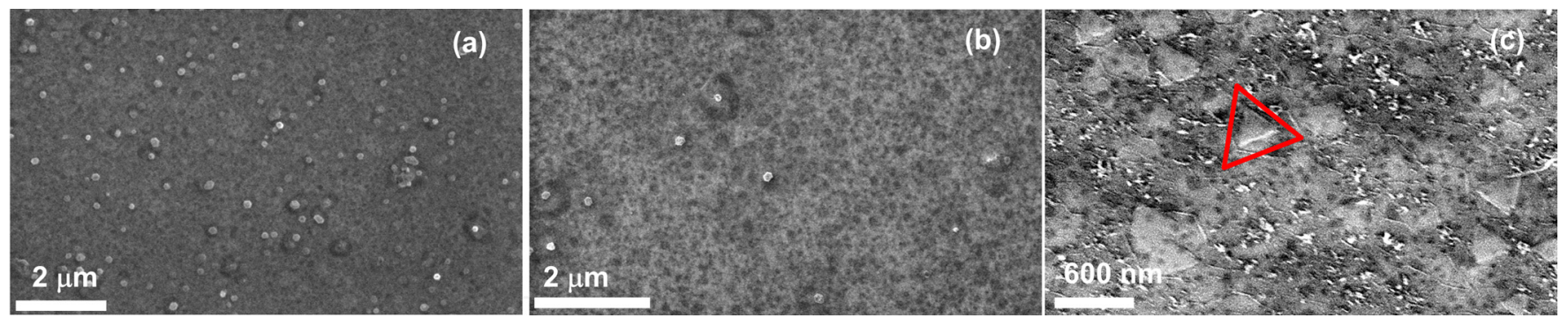

Fig. 1. (Color online) SEM images of films deposited on $\alpha-\mathrm{Al}_{2} \mathrm{O}_{3}$ for (a) $1 \mathrm{~min}$, (b) 5 min, and (c) 20 min where one of the islands is highlighted with a red triangle.

determination of $2 \mathrm{D}$ versus $3 \mathrm{D}$ growth, we used the observation by Sutter and Sutter ${ }^{17}$ that the contrast in SEM when $\mathrm{sp}^{2}-\mathrm{BN}$ is under investigation is directly related to the thickness of the BN layer. To reduce the charging effect due to the dielectric nature of the $\mathrm{sp}^{2}$-BN, especially on the insulating $\alpha-\mathrm{Al}_{2} \mathrm{O}_{3}$ substrate, an acceleration voltage of $5 \mathrm{kV}$ was applied to the field emission gun.

\section{RESULTS AND DISCUSSION}

\section{A. Nucleation and structure evolution}

The early stages of $\mathrm{sp}^{2}$-BN thin film growth were investigated on $\mathrm{AlN} / \alpha-\mathrm{Al}_{2} \mathrm{O}_{3}$. As can be seen from Figs. 1(a)-1(c), formation of triangular-shaped islands with a typical lateral size of $\sim 500 \mathrm{~nm}$ is discernible on the surface after $20 \mathrm{~min}$ of growth [Fig. 1(c)]. The islands were evenly distributed on the surface, suggesting a layer-by-layer growth of $\mathrm{sp}^{2}-\mathrm{BN}$ for a limited thickness (growth time of $5 \mathrm{~min}<\mathrm{t}<20 \mathrm{~min}$ ) followed by a transition to island or mixed layer-by-layer with island growth mode $(t>20 \mathrm{~min})$. The hexagonal islands shown in Figs. 1(a) and 1(b) are associated with the underlying AIN buffer layer, and such islands were also observed on the surface of the $\alpha-\mathrm{Al}_{2} \mathrm{O}_{3}$ following nitridation (Fig. 2).

On $(0001) 6 \mathrm{H}-\mathrm{SiC}$, the formation of triangular-shaped islands is seen after 5 min of growth [Figs. 3(a)-3(c)], which is similar to that previously observed for $\mathrm{BN}$ growth on metallic substrates. $^{20-22}$ TEM shows the formation of a

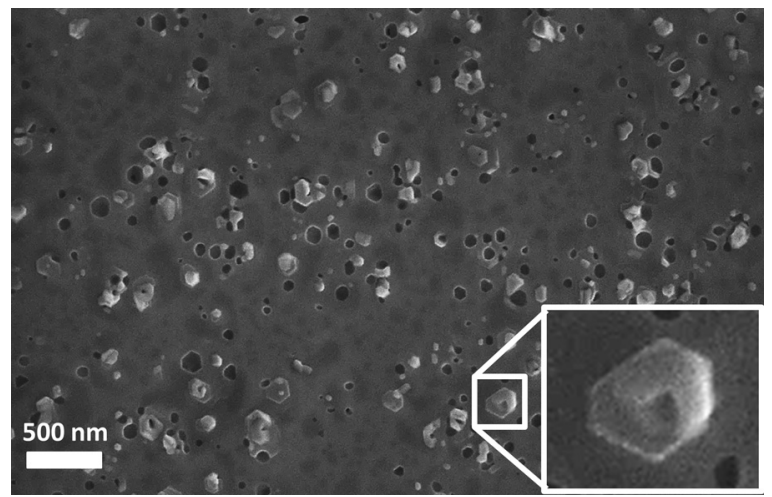

FIG. 2. SEM image of the AlN buffer layer formed on $\alpha-\mathrm{Al}_{2} \mathrm{O}_{3}$ by nitridation at $1500{ }^{\circ} \mathrm{C}$ for 10 min with $\mathrm{NH}_{3}$ concentration of $10 \%$ in $\mathrm{H}_{2}$ carrier gas and at a pressure of 70 mbar. The image shows the surface of the AlN buffer layer that allows concluding that islands observed in Fig. 1(a) are related to the buffer layer and not to $\mathrm{sp}^{2}$-BN. The inset shows 3.6 times magnified part of the surface. continuous layer of $\mathrm{sp}^{2}$-BN on the $\mathrm{SiC}$ substrate (supplementary Fig. 1). ${ }^{33}$ This continuous layer has not been observed on metallic substrates. Such growth behavior on the SiC substrate suggests layer-by-layer growth of $\mathrm{sp}^{2}$-BN to a limited thickness (growth time $\mathrm{t}<5 \mathrm{~min}$ ) followed by a transition to island growth mode, i.e., the characteristic of mixed layerby-layer and island growth modes. When studying SEM images obtained from $\mathrm{sp}^{2}$-BN films deposited for $20 \mathrm{~min}$, the surface of the film on $\mathrm{SiC}$ substrate appears to be covered by triangular-shaped islands with a density of $\sim 4.4 \mu \mathrm{m}^{-2}$ [Fig. 3(c)]. This can be compared to the well separated triangular islands visible on the $\mathrm{AlN} / \alpha-\mathrm{Al}_{2} \mathrm{O}_{3}$ with a density of $\sim 1.7 \mu \mathrm{m}^{-2}$ [Fig. 1(c)]. Thus, $\mathrm{sp}^{2}$-BN grows with a mixed layer-by-layer and island growth modes on both substrates while a transition to island growth mode occurs at a lower film thickness on $6 \mathrm{H}-\mathrm{SiC}$ compared to $\mathrm{AlN} / \alpha-\mathrm{Al}_{2} \mathrm{O}_{3}$.

XPS measurements on the layers deposited for $1 \mathrm{~min}$ on both substrates show the B 1s peak positioned at binding energies of around $189.5 \mathrm{eV}$ (see Fig. 4). This value is close to the reported value for $\mathrm{B}-\mathrm{N}$ bonding with binding energies in the range of 189.9-190.7 eV, ${ }^{8,16,34}$ which support the formation of BN. The minor peak shifts in Fig. 4 are likely an effect of the nonconducting sapphire and semiconducting $\mathrm{SiC}$ substrates, leading to charging effect of the sample and shift of the Fermi level.

From the TEM micrograph in Fig. 5, it can be seen that the atomic pairs of $\mathrm{sp}^{2}-\mathrm{BN}$ deposited on $\mathrm{AlN} / \alpha-\mathrm{Al}_{2} \mathrm{O}_{3}$ are positioned directly on top of each other. This shows h-BN formation on $\mathrm{AlN} / \alpha-\mathrm{Al}_{2} \mathrm{O}_{3} .{ }^{26}$ The film presented in Fig. 5 was deposited for $10 \mathrm{~min}$ at $1500^{\circ} \mathrm{C}$ with $\mathrm{N} / \mathrm{B}=643$ and pressure of 70 mbar and with 10 basal planes visible, which suggests a growth rate of $0.33 \mathrm{~nm} / \mathrm{min}$ (one basal plane per minute). This growth rate is more than ten times lower compared to the growth rate determined for the thick $(200 \mathrm{~nm})$ films being $4 \mathrm{~nm} / \mathrm{min}^{26,27}$ A slow initial nucleation step that is followed by an increasing growth rate is often encountered in growth of thin film materials by CVD, e.g., diamond ${ }^{35,36}$ and $\mathrm{SiC}^{37}$ In our previous work, a transition from h-BN to r-BN growth on $\mathrm{AlN} / \alpha-\mathrm{Al}_{2} \mathrm{O}_{3}$ occurred after approximately 13 basal planes of h-BN (Ref. 26) corresponding to a thickness of $4.3 \mathrm{~nm}$. The transition of the growth from h-BN to r-BN on $\mathrm{AlN} / \alpha-\mathrm{Al}_{2} \mathrm{O}_{3}$ may be a consequence of stress relaxation induced by the lattice mismatch. Furthermore, the critical thickness for $\mathrm{sp}^{2}$-BN growth on AlN by the Fischer's equation $^{5}$ is $3 \mathrm{~nm}$, which is in a good agreement with the 

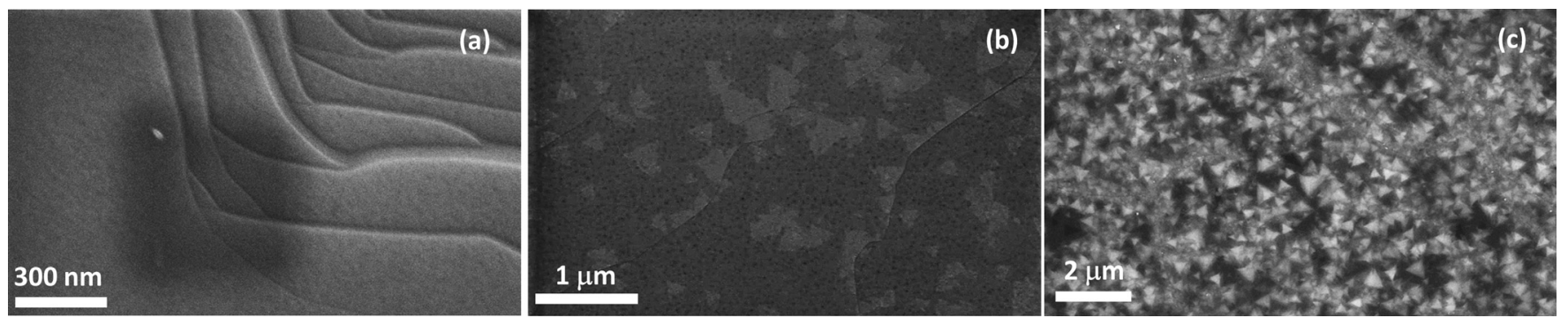

FIG. 3. SEM images of films deposited on $6 \mathrm{H}-\mathrm{SiC}$ for (a) $1 \mathrm{~min}$, (b) $5 \mathrm{~min}$, and (c) $20 \mathrm{~min}$.

experimentally observed h-BN thickness of $\sim 4 \mathrm{~nm}^{26}$ Similar to our previous work, ${ }^{26}$ we used GI-XRD measurements to support the formation of h-BN by observing the peak from the $\{10 \overline{1} 0\}$ planes of $\mathrm{h}-\mathrm{BN}$ and the peaks associated with the $\{11 \overline{2} 0\}$ planes of $\alpha-\mathrm{Al}_{2} \mathrm{O}_{3}$ and $\{10 \overline{1} 0\}$ planes of AlN (not shown). In addition, the $10 \overline{1} 0$ peaks of h-BN were found confined and $60^{\circ}$ separated in a $\phi$ scan suggesting epitaxial growth. This finding together with the observation that the basal planes of h-BN are parallel to the surface in the TEM micrograph leads to the conclusion that the h-BN film is grown epitaxially on the $\mathrm{AlN} / \alpha \mathrm{Al}_{2} \mathrm{O}_{3}$ with epitaxial relation (112̄0) $\alpha-\mathrm{Al}_{2} \mathrm{O}_{3}\|(10 \overline{1} 0) \mathrm{AlN}\|(10 \overline{1} 0) \mathrm{h}-\mathrm{BN}$ and (0001) $\alpha-\mathrm{Al}_{2} \mathrm{O}_{3}\|(0001) \mathrm{AlN}\|(0001) \mathrm{h}-\mathrm{BN}$. This agrees with our previous results. ${ }^{24,26}$ Thus, it is possible to deposit phase pure epitaxial h-BN layer up to the thickness of about $\sim 4 \mathrm{~nm}$ in a controlled way. The epitaxial growth determined by XRD suggests that the amorphous region at the interface visible in Fig. 5 is an effect of the sample preparation.

\section{B. Temperature effect on crystal evolution}

To investigate the influence of temperature, we successfully grew h-BN on $\alpha-\mathrm{AlN} / \alpha-\mathrm{Al}_{2} \mathrm{O}_{3}$ at $1200^{\circ} \mathrm{C}$, by adjusting the $\mathrm{N} / \mathrm{B}$ ratio and the $\mathrm{SiH}_{4}$ content to 750 and $1.2 \mathrm{ppm}$, respectively. This growth conditions were achieved by gradually adjusting N/B ratio and $\mathrm{SiH}_{4}$ flow where initial values were 640 and 0 , respectively. The higher concentration of ammonia needed at lower temperature is an effect of a lower concentration of active species produced from ammonia molecule at lower temperatures. ${ }^{38}$ The lower concentration

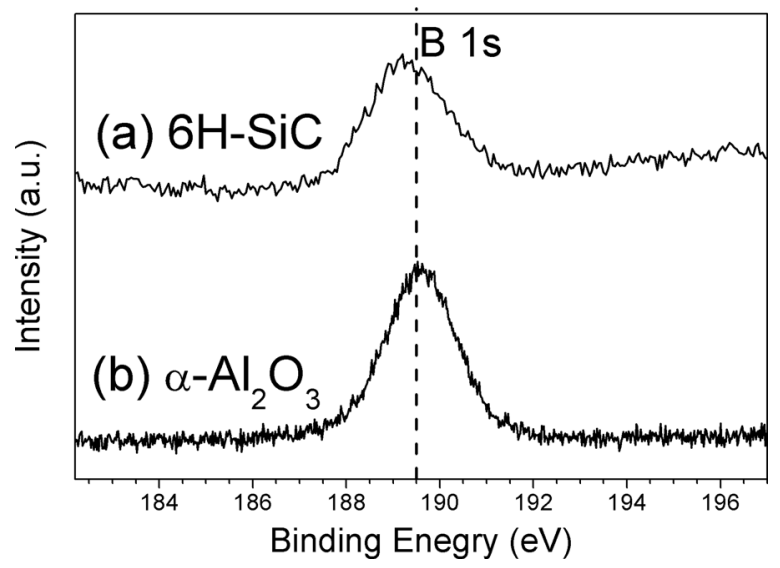

FIG. 4. XPS spectra of the B 1s peaks for films deposited for $1 \mathrm{~min}$ on (a) $6 \mathrm{H}-\mathrm{SiC}$ and (b) $\alpha-\mathrm{Al}_{2} \mathrm{O}_{3}$. of silane needed in the gas mixture at lower temperature can be attributed to a lower Si desorption rate from a less hot surface. The position of the h-BN 0002/r-BN 0003 XRD peak for the samples deposited at $1200^{\circ} \mathrm{C}$ is $26.65^{\circ} \pm 0.02^{\circ}$ in $2 \theta$, which differs from the typically observed value for samples deposited at $1500^{\circ} \mathrm{C}$ of $26.74^{\circ}$. This peak shift towards the reference value for t-BN $\left(26.3^{\circ}\right),{ }^{39}$ where lower $2 \theta$ value implies that the ordering of the basal planes are somewhat lower in films deposited at $1200^{\circ} \mathrm{C} .{ }^{40}$ To investigate the crystalline structure at the interface in layers deposited with short deposition time and a temperature of $1200^{\circ} \mathrm{C}$, we employed GI-XRD. Figure 6(a) shows $\theta-2 \theta$ scan where, similarly to high temperature grown layers, a peak associated with the $\{10 \overline{1} 0\}$ planes of h-BN is observed along with the peaks from the $\{11 \overline{2} 0\}$ planes of $\alpha-\mathrm{Al}_{2} \mathrm{O}_{3}$ and $\{10 \overline{1} 0\}$ planes of AlN and Fig. 6(b) shows a $\phi$ scan of the $\{10 \overline{1} 0\}$ planes of h-BN, which are separated by $60^{\circ}$. These results confirm the growth of h-BN on (0001) $\alpha-\mathrm{Al}_{2} \mathrm{O}_{3}$ substrate with an $\mathrm{AlN}$ buffer layer. The $\phi$ scan also shows the epitaxial growth of $\mathrm{h}$-BN at the temperature of $1200^{\circ} \mathrm{C}$. However, continuous growth of thicker film was difficult due to the formation of disordered, low density $\mathrm{sp}^{2}-\mathrm{BN}(\mathrm{t}-\mathrm{BN})$ that competes with crystalline material. The formation of such low density $\mathrm{sp}^{2}$ BN films takes place also at higher temperature, but after a longer growth time (thicker film). The formation of t-BN is likely to be induced by a reduction of the surface temperature caused by the poor thermal conductivity of $h-$ and $r-B N$ in the c-axis direction. Another problem associated with the growth at low temperature is the enhanced memory effect of the reactor caused by lower desorption rate of adsorbed $\mathrm{Si}$ at lower temperature that complicates the control of the $\mathrm{Si}$ concentration in the gas phase. This makes deposition at

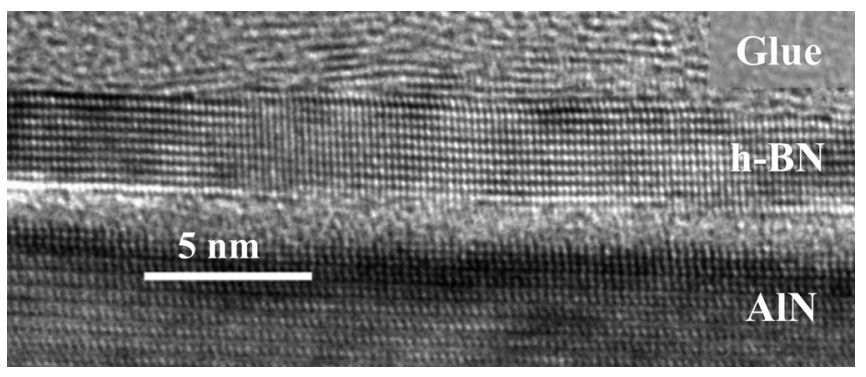

FIG. 5. HRTEM micrograph of a film deposited for $10 \mathrm{~min}$ on $\mathrm{AlN} / \alpha-\mathrm{Al}_{2} \mathrm{O}_{3}$. Alignment of the atomic planes in the BN film suggests formation of pure $\mathrm{h}$ $\mathrm{BN}$. The amorphous region between the AlN and h-BN could be an effect of interface amorphization or film exfoliation. 

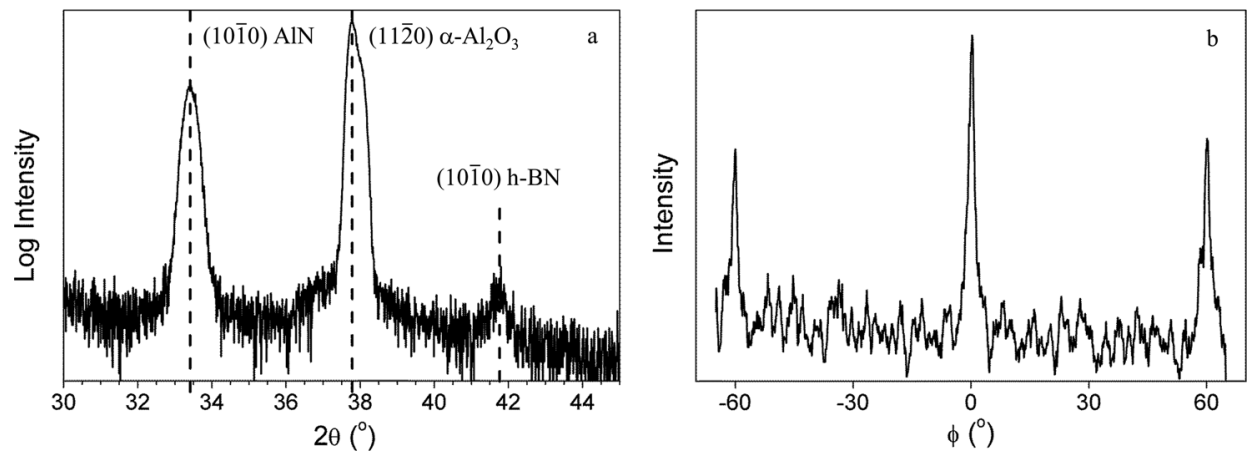

FIG. 6. GI-XRD patterns showing (a) $\theta-2 \theta$ scan and (b) $\phi$ scan of the film deposited on $\mathrm{AlN} / \alpha-\mathrm{Al}_{2} \mathrm{O}_{3}$ at $1200^{\circ} \mathrm{C}$ showing formation of epitaxial h-BN.

$1200^{\circ} \mathrm{C}$ hard to control and reproduce, and thus highly unstable, as can be seen in the supplementary Fig. 2 where the $0002 / 0003$ peak position of h-BN/r-BN in XRD is plotted as a function of the Si concentration in the gas mixture. ${ }^{33}$

For experiments on $6 \mathrm{H}-\mathrm{SiC}$, no peaks assigned to $\mathrm{h}-\mathrm{BN} / \mathrm{r}-$ BN $(0002) /(0003)$ planes in XRD or (1010) planes in GI-XRD in samples deposited below $1500{ }^{\circ} \mathrm{C}$. As a matter of fact, there were no XRD peaks visible corresponding to t-BN. However, peak characteristic of $\mathrm{sp}^{2}-\mathrm{BN}$ at $1370 \mathrm{~cm}^{-1}$ was observed in Fourier transform infrared interferometry (supplementary Fig. 3). ${ }^{33}$ From these observations, we conclude that a-BN is formed.

For $6 \mathrm{H}-\mathrm{SiC}$ substrates, growth experiments were conducted at higher temperatures. At $1600^{\circ} \mathrm{C}$, we found triangular-shaped islands characteristic for r-BN [Fig. 7(a)], but GI-XRD did not detect h-BN. A growth temperature of $1700^{\circ} \mathrm{C}$ was too high as the substrate was severely etched seen from the formation of etch craters [Fig. 7(b)].

From these observations, as well as previously observed differences in triangular island densities, we suggest that the growth of crystalline $\mathrm{sp}^{2}$ - $\mathrm{BN}$ requires higher temperature when $6 \mathrm{H}-\mathrm{SiC}$ substrate is employed compared to when AlN/ $\alpha-\mathrm{Al}_{2} \mathrm{O}_{3}$ is utilized. This suggests a lower mobility of $\mathrm{B}$ and $\mathrm{N}$ adatoms on the surface of $6 \mathrm{H}-\mathrm{SiC}$, which prevents them from finding and occupying correct sites necessary for the formation of crystalline material. This leads to higher nucleation density and promotes the formation of disordered $\mathrm{sp}^{2}$-BN. Even at the growth temperature of $1200^{\circ} \mathrm{C}, \mathrm{h}-\mathrm{BN}$ formation is achieved on $\mathrm{AlN} / \alpha-\mathrm{Al}_{2} \mathrm{O}_{3}$ but r-BN only forms on $6 \mathrm{H}-\mathrm{SiC}$ substrate at higher growth temperatures $\left(\mathrm{T} \geq 1500^{\circ} \mathrm{C}\right)$. We conclude that the growth of different $\mathrm{sp}^{2}$-BN polytypes has a substrate promoted behavior, as discussed in our previous work. ${ }^{26}$

\section{SUMMARY AND CONCLUSIONS}

h-BN was deposited on (0001) $\mathrm{AlN} /(0001) \alpha-\mathrm{Al}_{2} \mathrm{O}_{3}$ at temperatures of 1200 and $1500{ }^{\circ} \mathrm{C}$ with an estimated growth rate of $0.33 \mathrm{~nm} / \mathrm{min}$. Following $12 \mathrm{~min}$ deposition time at $1500^{\circ} \mathrm{C}$, a transition occurs from h-BN to r-BN, corresponding to a film thickness of $4 \mathrm{~nm}$ according to our recent HRTEM observation. This transition is supported from the formation of triangular islands characteristic of r-BN, which are observed in SEM after $20 \mathrm{~min}$ of growth. The h-BN growth evolves in a layer-by-layer growth mode, but for $\mathrm{r}-\mathrm{BN}$, this is followed by a mixed layer-by-layer and island growth mode. The change in $\mathrm{sp}^{2}-\mathrm{BN}$ phase on $\mathrm{AlN} / \alpha-\mathrm{Al}_{2} \mathrm{O}_{3}$ substrate is suggested to be an effect of stress relaxation induced by the lattice mismatch. In contrast, on $6 \mathrm{H}-\mathrm{SiC}$ substrates phase pure r-BN film grows directly with a mixed layer-by-layer and island growth mode.

The formation of different $\mathrm{sp}^{2}$-BN polytypes is independent of the growth temperature, as h-BN forms on $\alpha-\mathrm{Al}_{2} \mathrm{O}_{3}$ already at $1200^{\circ} \mathrm{C}$ and growth transition from h-BN to r-BN occur after the critical film thickness at $1500^{\circ} \mathrm{C}$ and r-BN grows directly on $6 \mathrm{H}-\mathrm{SiC}$ at temperatures equal or higher than $1500^{\circ} \mathrm{C}$. From these observations, the r-BN polytype is proposed to be thermodynamically favorable phase at our applied growth conditions.

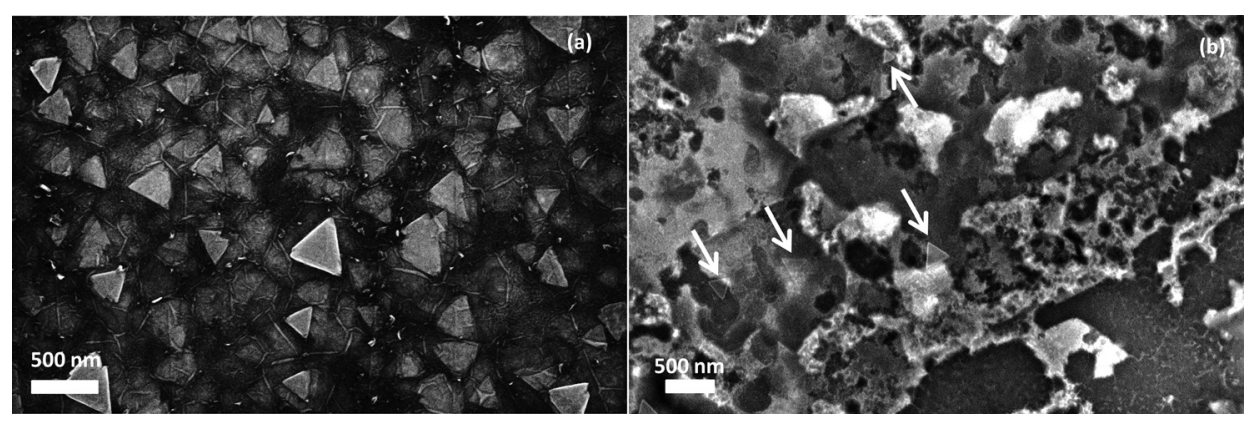

FIG. 7. SEM images of films deposited on $6 \mathrm{H}-\mathrm{SiC}$ substrate at (a) $1600^{\circ} \mathrm{C}$ and (b) $1700^{\circ} \mathrm{C}$. Triangular-shaped islands that are characteristic for r-BN are observed at both conditions while at the temperature of $1700^{\circ} \mathrm{C}$ size and density of such triangles are lower than at growth temperature of $1600{ }^{\circ} \mathrm{C}$. In the right image, due to low contrast of the triangles on the background, white arrows are pointing on some of them. 


\section{ACKNOWLEDGMENTS}

Sven G. Andersson is gratefully acknowledged for his help in maintaining the CVD equipment. This work was supported by the Swedish Research Council (VR: Grant No. 621-20135585), Carl Tryggers Stiftelse (No. 12:175), and the CeNano Program at Linköping University. H.H. acknowledges support from the Swedish Government Strategic Research Area in Materials Science on Functional Materials at Linköping University (Faculty Grant SFO-Mat-LiU No. 2009-00971). Z.C. acknowledges the support of Bolyai Janos research scholarship of Hungarian Academy of Sciences.

${ }^{1}$ S. Strite and H. Morkoc, J. Vac. Sci. Technol. B 10, 1237 (1992).

${ }^{2}$ X. Sun, D. Li, Y. Chen, H. Song, H. Jiang, Z. Li, G. Miao, and Z. Zhang, CrystEngComm 15, 6066 (2013).

${ }^{3}$ K. Hiramatsu, S. Itoh, H. Amano, and I. Akasaki, J. Cryst. Growth 115, 628 (1991).

${ }^{4}$ C. Kim, I. K. Robinson, J. Myoung, K. Shim, M. C. Yoo, and K. Kim, Appl. Phys. Lett. 69, 2358 (1996).

${ }^{5}$ A. Fischer, H. Kuhne, and H. Richter, Phys. Rev. Lett. 73, 2712 (1994).

${ }^{6}$ R. F. Davis, R. D. Bremser, W. G. Perry, and K. S. Ailey, J. Eur. Ceram. Soc. 17, 1775 (1997).

${ }^{7}$ M. C. Polo, M. B. el Mekki, J. L. Andujar, N. Mestres, and J. Pascual, Diamond Relat. Mater. 6, 1550 (1997).

${ }^{8}$ M. Anutgan, T. Aliyeva Antugan, E. Ozkol, I. Atilgan, and B. Katircioglu, J. Non-Cryst. Solids 355, 1622 (2009).

${ }^{9}$ Y. Kobayashi, T. Akasaka, and T. Makimoto, J. Cryst. Growth 310, 5048 (2008).

${ }^{10}$ R. Y. Tay, M. H. Griep, G. Mallick, S. H. Tsang, R. S. Singh, T. Tumlin, E. H. T. Teo, and S. P. Karna, Nano Lett. 14, 839 (2014).

${ }^{11}$ S. Le Gallet, G. Chollon, F. Rebillat, A. Guette, X. Bourrat, R. Naslain, M. Couzi, and J. L. Bruneel, J. Eur. Ceram. Soc. 24, 33 (2004).

${ }^{12}$ R. Y. Tay, X. Wang, S. H. Tsang, G. C. Loh, R. S. Singh, H. Li, G. Mallick, and E. H. T. Teo, J. Mater. Chem. C 2, 1650 (2014).

${ }^{13}$ M. T. Paffett, R. J. Simonson, P. Papin, and R. T. Paine, Surf. Sci. 232, 286 (1990).

${ }^{14}$ R. Dahal, J. Li, S. Majety, B. N. Pantha, X. K. Cao, J. Y. Lin, and H. X. Jiang, Appl. Phys. Lett. 98, 211110 (2011).

${ }^{15}$ R. Y. Tay, S. H. Tsang, M. Loeblein, W. L. Chow, G. C. Loh, J. W. Toh, S. L. Ang, and E. H. T. Teo, Appl. Phys. Lett. 106, 101901 (2015).
${ }^{16}$ L. Song et al., Nano Lett. 10, 3209 (2010).

${ }^{17}$ P. Sutter and E. Sutter, APL Mater. 2, 092502 (2014).

${ }^{18}$ A. Hemmi et al., Rev. Sci. Instrum. 85, 035101 (2014).

${ }^{19}$ A. Gibb, N. Alem, and A. Zettl, Phys. Status Solidi B 250, 2727 (2013).

${ }^{20}$ C. J. Kim, L. Brown, M. W. Graham, R. Hovden, R. W. Havener, P. L. McEuen, D. A. Muller, and J. Park, Nano Lett. 13, 5660 (2013).

${ }^{21}$ S. M. Kim, A. Hsu, P. T. Araujo, Y. H. Lee, T. Palacios, M. Dresselhaus, J. C. Idrobo, K. K. Kim, and J. Kong, Nano Lett. 13, 933 (2013).

${ }^{22}$ S. Joshi et al., Nano Lett. 12, 5821 (2012).

${ }^{23}$ P. Sutter, J. Lahiri, P. Zahl, B. Wang, and E. Sutter, Nano Lett. 13, 276 (2013).

${ }^{24}$ M. Chubarov, H. Pedersen, H. Högberg, V. Darakchieva, J. Jensen, P. O. Å. Persson, and A. Henry, Phys. Status Solidi RRL 5, 397 (2011).

${ }^{25}$ M. Chubarov, H. Pedersen, H. Högberg, Zs. Czigany, and A. Henry, CrystEngComm. 16, 5430 (2014).

${ }^{26}$ M. Chubarov, H. Pedersen, H. Högberg, Zs. Czigany, M. Garbrecht, and A. Henry, Chem. Mater. 27, 1640 (2015).

${ }^{27}$ M. Chubarov, H. Pedersen, H. Högberg, and A. Henry, CrystEngComm 15, 455 (2013).

${ }^{28} \mathrm{~K}$. A. Reinhardt and W. Kern, Handbook of Silicon Wafer Cleaning Technology (Elsevier Inc., 2008).

${ }^{29}$ J. Hassan, J. P. Bergman, A. Henry, and E. Janzen, J. Cryst. Growth 310, 4430 (2008)

${ }^{30}$ M. Chubarov, H. Pedersen, H. Högberg, J. Jensen, and A. Henry, Cryst. Growth Des. 12, 3215 (2012).

${ }^{31}$ N. Ooi, A. Rairak, L. Lindsley, and J. B. Adams, J. Phys.: Condens. Matter 18, 97 (2006).

${ }^{32}$ Á. Barna, Mater. Res. Soc. Symp. Proc. 254, 3 (1992).

${ }^{33}$ See supplemental material at http://dx.doi.org/10.1116/1.4935155 for additional clarifying figures.

${ }^{34}$ Y. Shi et al., Nano Lett. 10, 4134 (2010).

${ }^{35}$ J. Wei, J. M. Chang, and Y. Tzeng. Thin Solid Films 212, 91 (1992).

${ }^{36}$ H. Sternschulte, M. Schreck, and B. Stritzker, Diamond Relat. Mater. 11, 296 (2002).

${ }^{37}$ A. Henry, L. Storasta, and E. Janzén, Mater. Sci. Forum 433-436, 153 (2003).

${ }^{38}$ B. Beaumont, P. Gibart, and J. P. Faurie, J. Cryst. Growth 156, 140 (1995).

${ }^{39}$ Joint Committee on Powder Diffraction Standards, JCPDS, Swarthmore, PA, pattern 34-0421; pattern 45-1171 (1998).

${ }^{40}$ C. Schimpf, M. Motylenko, and D. Rafaja, Mater. Charact. 86, 190 (2013). 